\title{
Thinking in Bilingual Teaching Practice for Industrial Analysis
}

\author{
Haiyan DU ${ }^{1, a}$, Weiming $\mathrm{WU}^{2, \mathrm{~b}}$, Jing $\mathrm{FAN}^{1, \mathrm{c}}$ \\ ${ }^{1}$ School of Metallurgical and Chemical Engineering, Jiangxi University of Science and Technology, \\ Ganzhou, 341000, China \\ ${ }^{2}$ Institute of Engineering Research, Jiangxi University of Science and Technology, Ganzhou, \\ 341000, China \\ adhyboy@163.com, bwwmwhx@163.com, '772955169@qq.com
}

Keywords: Bilingual teaching, Influence factors, Industrial Analysis, feasibility.

\begin{abstract}
Combined with the purpose, significance and practice of "industrial analysis" bilingual teaching, the feasibility of "industrial analysis" bilingual teaching has been analyzed from the aspects of teacher, student and resource. While the main influence factors on the effectiveness of "industrial analysis" bilingual teaching has also been stated, such as teachers construction, students request, teaching material, educational methods, laboratory resource utilization, and so on. Finally, this paper summarizes the practical experience of "industrial analysis" bilingual teaching, and concludes the effect of bilingual teaching on the English level and professional knowledge of teachers and students. It provides the reference for the bilingual teaching of other courses and promotes the development of bilingual teaching work.
\end{abstract}

\section{Introduction}

With the rapid development of economy, science and society, more and more attention has been paid to the professional English communication and the professional application field of English other than a tool of the language teaching and application ${ }^{[1]}$. In 2001, China's national ministry of education stated that "In order to achieve 5\% 10\% of curriculum in three years for the bilingual teaching courses ${ }^{[2]}$, the use of foreign language such as English should be actively promoted in teaching." At the same time, the bilingual teaching is also the inevitable result of higher education internationalization. International education institutions driven by economic globalization began to enter into the education market of China gradually, and higher education international competition will be more and more fierce. Thus, it is of significant importance that universities increase the encouragement and support of bilingual teaching.

In recent years, most of universities in China have begun to implement bilingual teaching, expecting that complex talents who are proficient in both professional knowledge and foreign language will be brought up. In order to meet the demand for high quality talents in China, Jiangxi university of science and technology has offered "industrial analysis" bilingual course for chemical engineering students.

\section{The Feasibility of "Industrial Analysis" Bilingual Teaching}

In teachers aspect, many foreign teachers were engaged from abroad as perennial teachers in Jiangxi university of science and technology, while many Chinese teachers were sent to foreign countries to have a language training. In addition, the university carries out international exchanges and cooperation actively, establishing a communication and cooperation relationship with many university and enterprise of foreign countries, such as America, England, Holland, Iceland, Brazil, and so on, especially with Thailand Prince of Songkla University for more than 10 years of cooperation and communication. A comprehensive high quality teachers' team has been created which is very reasonable in age, education and professional title structure, and experienced not only in teaching and research, but also in specialized knowledge and English language. This lays a solid foundation for bilingual teaching activities. 
In students aspect, the old rigid learning of many years reduces the students' interest of classroom learning, and the students are especially tired of the study without interaction, thus teaching efficiency is low. Bilingual teaching, however, can make the classroom lively and vividly. Researches show that operation can focus students' attention and strengthen independent thinking. It is obvious that in "industrial analysis" bilingual teaching process, the teacher can make full use of the resources in the laboratory, and encourage students to communicate with each other in English in the course of experiments. In fact for students that is feasible and the English oral ability and English skills will be improved because they have good foundation in basic English.

In resources aspect, Jiangxi university of science and technology has been equipped with advanced laboratory with good environment, and it invests more than ¥ 20 million for laboratory construction every year. A lot of analytical instruments were brought into the laboratory and a large part of them take English as working languages. It provides plenty of hardware devices for "industrial analysis" bilingual teaching, and makes "industrial analysis" course to take the lead in carrying out bilingual teaching, and integrates with international market as soon as possible.

\section{The Main Influence Factors on the Effect of "Industrial Analysis" Bilingual Teaching}

Teachers. In the implementation of bilingual teaching process, the key issue is the teacher. Only when there is a teacher team, in which teachers have been trained to have both solid specialized knowledge and high foreign language level, can the progress of the bilingual teaching be smooth [3-8]. Therefore, special attention should be paid to the construction of the teaching staff in the process of bilingual teaching. By choosing, training or external introduction, a good bilingual teacher team can be created.

Students. Before the bilingual teaching, students have mastered some basic English and specialized knowledge, that lays the foundation for the bilingual teaching. Moreover, the bilingual link stimulates the students' appetites for further professional study. However it is not difficult to find that students' English level is totally different. some students lack the vocabulary and their listening is poor, they can't meet the requirements of bilingual teaching. For those students university will firstly provide them with the training in order to improve their basic language skills, then the teaching and learning effect can be ensured.

Resources. Teaching material: The selection and use of teaching material will directly relate to the effect of bilingual teaching, so the choice of teaching material should be very cautious. Teaching material not only should meet the requirement of teaching, but also suit the students' English level. According to the principle of the applicability and practicability teaching materials are selected. Recommend the following books as teaching materials or reference books: " industry analysis professional English » by Jucen Li; « CONTEMPORARY INSTRUMENTAL ANALYSIS " by Kenneth A.R ubinson, Judith F.R ubinson; "CHEMISTRY-The Central Science » by Theodore 1. Brown and Student's Guide « CHEMISTRY-The Central Science » by James C. Hill; and so on.

Educational methods: Teaching and learning can be carried out mainly by the multimedia courseware as a auxiliary way. The picture, sound recording, video recording, etc in the multimedia courseware can vividly transfer teaching contents to students so that it can attract students attention, mobilize students' enthusiasm, increase teaching interest and let students grasp professional knowledge and improve English level easily. The use of multimedia courseware makes the bilingual teaching activities proceed more smoothly.

Laboratory resource utilization: Whether the rich equipment resource of the laboratory can be made use of is directly related to the effect of "industrial analysis" bilingual teaching. In the process, various kinds of large and small experimental equipments most of them from abroad can stimulate the senses of students and the desire to express in English. The communication among the teachers and students should be required to speak in English as much as possible. Then that will make students mobilize their learning potential, improve their English level and expand their vocabulary in imperceptible condition. Finally the teaching efficiency will be improved. 


\section{"Industrial Analysis" Bilingual Teaching Practice.}

Optimizing teaching management. The optimization of bilingual teaching materials is as crucial as the choice of it. Based on specific situation and problems, the optimization of material will be improved constantly in the teaching practice. The teaching materials should also meet the teaching requirement and interest the students. The continuous optimization of bilingual teaching modes and methods should be combined with students' learning situation. Measures suitable for the local conditions should be taken to form deep learning atmosphere, apart from the ways of group discussion, situational dialogues and multimedia teaching methods. At the same time, the laboratory should take a series of measures, such as the introduction of advanced equipment and the increase of feasible experiments, to deepen the impression on students and arouse the learning potential of students.

The optimization of the network resource can proceed just the same. Bilingual course website with lesson plan, course exercises, and other learning materials can first be established, students can preview lessons before class and review the lessons after class all through the web, they can remove their confusion in the heart and raise self-study ability and discuss easily in the classroom. Thus the contents of web should be optimised in great detail.

Dealing with the relationship between language teaching and professional teaching. Bilingual teaching isn't a simple language teaching, but is an organic combination of professional teaching and language teaching. Namely, bilingual teaching makes students master the professional knowledge, form English thinking, and improve the ability for listening, speaking, reading and writing of the professional English. And students will learn how to access the English literature and apply English to search for professional information, that lays a solid foundation for students' professional learning to be the international forefront.

Teachers team-building. Teachers are the most significant in bilingual teaching. Teachers needed in bilingual teaching should not only have the comprehensive ability of English, but also have rich teaching experience and the solid specialized skills, that will makes bilingual teaching get more notable achievements.

In the construction of teachers ${ }^{[9-11]}$, the university authority should have a plan to send the professional teachers who are good at foreign language to a good bilingual teaching college or some English training institutions for a short-term study by stages and need to invite bilingual teaching masters or senior experts for introducing their experience, doing part-time teaching, practice instruction, seminars, academic communication and so on when strengthening the construction of the teaching staff. It is more convenient for the teachers and students to contact and enjoy all kinds of profession resources.

Effect and benefit. After the "industry analysis" bilingual teaching, most of the chemical engineering students think that bilingual teaching is very necessary, only a few students hold that it is difficult to learn in the bilingual teaching process. Due to the lack of vocabulary, they must spend much more time on the preparation before class and review after class. Besides, their professional English listening and writing ability also needs to be further improved. Although science and engineering students have difficulties in learning English, the practice using English for the professional course is very popular with the students ${ }^{[12]}$.

Bilingual teaching can not only make students understand and grasp professional knowledge, but also help them widen sight, expand professional English vocabulary, improve English listening, speaking, reading and writing, and enhance the cognitive ability. In the bilingual teaching process, the oral English and teaching innovation ability of teachers will also be improved.

\section{Conclusions.}

Bilingual teaching is still in the stage of exploration. However with the economic globalization and the development of the information society, it is a great trend that education with bilingual teaching becomes international in the progress of higher education ${ }^{[13-15]}$. At the same time, the bilingual teaching of professional knowledge will be better and better under continuous efforts of 
the scholars, bilingual teaching activities of every school achieve the obvious effects. Thus it is necessary to support the bilingual teaching strongly, strive to exercise the student's professional English ability, enhance the overall quality of students, and promote the common progress of the teachers and students, in order to cultivate a large number of high quality talents for the world.

\section{Acknowledgements.}

The author would like to thank for the financial support by the quality engineering project of Education Department of Jiangxi Province: bilingual education model curriculum-—industrial analysis.

\section{References}

[1] Lixin Zhang: Chemical Education. 9(2006), p.32 (in Chinese)

[2] Jufeng Ye: Shanghai Engineering Technology University Education Research. 2(2003), p.14 (in Chinese)

[3] Zhuang Li, Baolin Wu: Higher Education Forum. 3(2007), p.79(in Chinese)

[4] Jianfeng Dong: Software Guide, 2(2012), p.194 (in Chinese)

[5] Shuhong Ma and Yuanqing Wang: Journal of Shijiazhuang Institute of Railway Technology. 10(2011), p. 105 (in Chinese)

[6] Yuqin Fu, Baoming Ji, Weizhou Wang: Journal of Luoyang Normal College.30(2011),P.57 (in Chinese)

[7] Jianguo Yu, Bing Wang, Feng Yan: China's Science and Education Innovation Tribune. 26(2011), P.130 (in Chinese)

[8] Xiaohua Huang, Jing Yang, Bang Li: University of Chemical. 20(2005), p.18 (in Chinese)

[9] Lina A R. J: Psycholinguistic Research. 21(1992), p.303

[10] Genesse F, Tucker G R, Lambert W E: Child Development. 46(1975), p.1010

[11] Saer D J: The British Journal of Psychology. 14(1923), p. 25

[12] Jingjing Deng: Journal of Military Surgeon in Southwest China. 9(2007), p.111 (in Chinese)

[13] Jinshu Han: Second International Workshop on Education Technology and Computer Science. 2(2010), p.441 (in Chinese)

[14] Shuxia Liu, Jianlun Sheng: International Conference on Educational and Information Technology. 2(2010), p. 453 (in Chinese)

[15] Ailing Gong and Tingrui Liu: First International Workshop on Education Technology and Computer Science. 1(2009), p.40 (in Chinese) 